\title{
Antimonopolism, a monomania and intellectual cul-de-sac of the neo left. [Note]
}

\author{
Camille Akmut
}

- I was there to smash the fascists in Spain!-, claims an aging anarchist, university professor, in the movie Slacker. His daughter correctly observes that this would have been impossible since he only traveled to that region of the world much later, (in the 1950s, on a honeymoon?), decades after the events...

A weak theory has resurfaced in the eclectic and often confused heads of, urban, tech, anarcho-minded thinkers of the wider California area.

Born somewhere in a SF gloryhole or sports bar, amid salty nuts, musky scents, and nonsensical ideas, resurfacing periodically in unknown places and untold orifices of the Brooklyn and Austin areas, antimonopolism is the current monomania and intellectual cul-de-sac of a portion of the pretend left;

instantly recognizable by their predilection for flashy-flimsy ideas ("If we lived in a postscarcity society, I would not work at Google", as found randomly on social media among other monumental stupidities), colorful hair colors and oddball clothing;

Its adherents are guided by the belief that monopolies are either the greatest threat or one of the greatest threats facing humanity; the exact extent of which varies from interpreter to interpreter, and from sunup to sundown.

These intellectuals with a small $\mathrm{i}$ - fashioned in the image of the brand designed in that sunny State - are of the reformist kind, to be sure. Meaning : " $L a$ revolucion!", but only if sung in a Cuban themed restaurant, with a sidedish of mild vegetables and butter corn.

Capitalism generates its own critiques, some evidently less potent than others.

"If we could destroy monopolies, all would be good, and all would be swell, and all would be whole and holy again". Like blinding chrome wheels spinning in the California sun, their nursery tale goes...

[According to C.D., exercising monopoly critique is akin to the revolutionary role played by the rallying cause of ecology.]

Leading this trend with EFF credentials is Cory Doctorow - a nice fellow to be clear, a good chap, a real propa' mate, if there was ever one he was - who, 
having only recently understood the full point and importance of free software, will no doubt soon understand Marx and Engels, in 40 or 50 years from now...

Chomsky himself reluctantly admits that the pair had had "some good ideas", a dubious euphemism (analogous to a featherweight boxer hypothetically describing Mike Tyson "a rather impressive gentleman"), hence communist theory can't be all that bad.

This is as gentle a tap on the bottom as possible :

Even in the unlikely event of the entirety of Big Tech, Big Finance, Big Entertainment, (and even "Big anime"!), being broken up tomorrow morning through a science-fiction like sudden and spontaneous alliance of cross-political forces, such transformation of the ways in which business is conducted would solve very little about the main issue, which remains capitalism.

The end product - spoiler alert! - would merely be a gentler form of capitalism.

But, capitalism, no matter how gentle, and no matter who wields the whip and how hard it comes crashing down, remains capitalism. Exploitation remains exploitation nonetheless. Even in the hands of a most gentle and understanding master.

Antimonopolism is a cul-de-sac theory, a road that leads to nowhere or no further (endless bargaining excepted, of course), a malady of the reformist mind, which Lenin had aptly described as the back and forth exchange of concessions and removal of previous gains generating the false impression of progress.

A moderately sized company boss is no kinder than a big CEO, as everyone who has worked in small- or mid-sized companies knows.

Replacing one greedy person by a thousand won't bring any long-lasting liberation to anyone.

Capitalists do not reject criticism, but pick the one they can handle best.

In Doctorow, EFF et al, the capitalist - big and small - knows he has found solid long-lasting friends... Their debates always end up in handshakes and pleasant jokes.

The former knows they have little to fear from the State (an "organ of the Bourgeoisie"), the other wants to have their turn, and what better philosophy to serve both than antimonopolist utopia promises...

Capitalist enterprises elect those critics they can best deal with and integrate, put them in the foreground, giving them an importance they never deserved.

And, when a science fiction writer finds no better premise for a novel than a software engineer creating programs used in the surveillance of BLM activists, the degree zero of speculative narrative is attained.

Ref. and commentary

Linklater, Richard. 1990. Slacker. 
(The Austin demi-monde of mass unemployment, deep state conspiracy theorists or truth sayers, real crime novelists, too-cool-for-school Tarot reading girls, professors with failing memories, botched robberies.)

_ D'Anastasio, Cecilia. 2021. "Welcome to the Era of Big Anime". Wired, $31 / 08$.

Doctorow, Cory. 2020. "We Used to Have Cake, Now We've Barely Got Icing". HOPE keynote and other events. https://media.ccc.de/

- Doctorow, Cory. 2021. Keynote linux.conf.au

(A review and summary is found here: https://lwn.net/Articles/844102/)

_ https://rms-open-letter.github.io/ and https://www.eff.org/deeplinks/2021/03/statementre-election-richard-stallman-fsf-board

The EFF and affiliated Tor Project, dedicated as they notoriously are to freedom of speech and human rights, call for full or partial social death of a person. Ohoh, this can't be good...

- 2021. "Inside BLM co-founder Patrisse Khan-Cullors' million-dollar real estate buying binge". NY Post, 10/04.

(You go girl : You go scoop up them houses right in the middle of a pandemic! Fred Hampton had understood more at age 21 than you ever have in your chaotic, disoriented long life) 